\title{
What do remote scientific meetings provide us?
}

\author{
Yasushi Sakata ${ }^{1}$
}

Received: 6 August 2021 / Accepted: 10 August 2021

(c) The Japan Society of Ultrasonics in Medicine 2021

It has been one and half years since COVID-19 began sweeping the world. To prevent densification, the Annual Meeting of the Japanese Circulation Society was completely web-based in 2020 and hybrid in 2021. The same is true for the American Heart Association (AHA) and the European Society of Cardiology (ESC). Many other conferences and meetings have changed from on-site to remote.

The advantages and disadvantages of remote meetings are becoming apparent. The advantage is improvement in the ability to collect information. In 2020, I participated in the 61st Annual Meeting of the Japanese Society of Clinical Virology for the first time. Initially, the conference was scheduled to be held in Niigata in June, and I would not have been able to attend due to a schedule conflict. Instead, I participated in intensive online lectures on COVID-19 from many of Japan's leading experts at a reasonable cost without needing to travel. Now, I can view many types of on-demand lessons at any time of the day, or put in another way, even while lying down. This is a tremendous advantage for information gathering.

On the other hand, the disadvantage is the lack of mutual discussion. We must post questions and answers in the chat room, even for general oral presentations. You can raise your hand and be nominated in some cases, but this is not easy to manage in a large conference. In the panel discussions, the speakers line up "on the stage", but the talks are rarely cordial due to the time difference in the audio.

Many of you may be thinking that this was also the case in the past. Very few of us could indeed ask questions even at large academic conferences held locally. Panel discussions were often filled with anticipated questions and failed to gain momentum due to time constraints. However, what happened afterward was different. After the session, I used to walk around and deepen my knowledge and interest by

Yasushi Sakata

yasushisk@cardiology.med.osaka-u.ac.jp

1 Department of Cardiovascular Medicine, Osaka University

Graduate School of Medicine, Osaka, Japan discussing topics with my colleagues and friends. We talked about whether the presentation was engaging, applicable to my research, or whether it was "true". I deepened friendships with them, and we confirmed each other's research themes. Yes, local conferences are always experienced with others, while web conferences are always experienced "all alone".

In the future, when COVID-19 converges, how will the format of academic conferences change? Will we introduce virtual reality using $5 \mathrm{G}$ ? That is, will we enter the virtual space as avatars, listen to lectures, and ask questions in the virtual area? Or will we pay for transportation, make arrangements to close outpatient clinics, go to the site, meet face to face, and have direct contact with each other to get the message across?

I believe that the direction in which academic conferences will go in the future is closely related to the direction in which our medical care will go. Patients will demand reasonable remote care as long as we provide medical care that does not require direct contact. And only when they want to consult with doctors about their illnesses instead of thinking "all alone", or when they want us to treat them by touching their bodies and minds, they will visit our clinics even if they have to pay more. COVID-19 has not brought about this change. It is just an acceleration of what has been going on for some time. Looking at the changes that scientific meetings have undergone, we should sense that the environment surrounding our practice has changed and that we are required to change with it.

Publisher's Note Springer Nature remains neutral with regard to jurisdictional claims in published maps and institutional affiliations. 